\title{
Kinetics of Dissolution of Copper-Zinc Alloy in Nitric-Sulfuric Acid Solutions
}

\author{
Natalya M. Vostrikova and Elena D. Kravtsova* \\ Siberian Federal University \\ 79 Svobodny, Krasnoyarsk, 660041, Russia
}

Received 16.06.2018, received in revised form 15.01.2019, accepted 07.02.2019

\begin{abstract}
Studies were carried out on the dissolution of a copper-zinc alloy imitating a base substrate of an electron scrap containing noble metals in nitric-sulfuric acid solutions. A mathematical model is obtained that allows calculating the rate of copper and zinc transition to nitric-sulfuric solutions by varying the concentration of $\mathrm{H}^{+}$ions from 1 to $4 \mathrm{~g}$-ion $/ \mathrm{dm}^{3}$ and $\mathrm{NO}_{3}^{-}$ions from 0,5 to $1,0 \mathrm{~g}$-ion $/ \mathrm{dm}^{3}$. In the range of concentrations of $\mathrm{H}^{+}$and $\mathrm{NO}_{3}^{-}$ions studied, the maximum rate of copper transition into the solution is $6,5 \cdot 10^{-5}$, and zinc is $4,5 \cdot 10^{-5} \mathrm{~kg} / \mathrm{m}^{2} \mathrm{~s}$.

The equation of regression allowing to carry out a choice of conditions for proceeding with necessary speed of the chemical processes taking place in metallurgical practice is presented.
\end{abstract}

Keywords: copper, zinc, brass, recycling.

Citation: Vostrikova N.M., Kravtsova E.D. Kinetics of dissolution of copper-zinc alloy in nitric-sulfuric acid solutions, J. Sib. Fed. Univ. Eng. technol., 2019, 12(2), 214-221. DOI: 10.17516/1999-494X-0130.

\section{Кинетика растворения медно-цинкового сплава \\ в азотно-сернокислых растворах}

Н.М. Вострикова, Е.Д. Кравцова

Сибирский федеральный университет Россия, 660041, Красноярск, пр. Свободный, 79

Проведены исследования по растворению медно-цинкового сплава, имитирующего неблагородную основу электронного лома, содержащего благородные металль в азотносернокисльх растворах. Получена математическая модель, позволяющая рассчитать скорость перехода меди и циинка в азотно-сернокислье растворы при варьировании концентрации

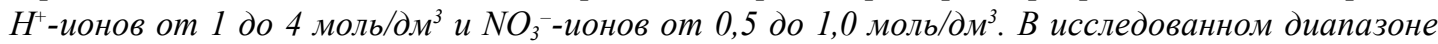
концентраций $\mathrm{H}^{+}-$и $\mathrm{NO}_{3}^{-}-$ионов максимальная скорость перехода меди в раствор составляет $6,5 \cdot 10^{-5}$, а циинка $-4,5 \cdot 10^{-5} \mathrm{\kappa} / \mathrm{M}^{2}$ c. Представлено уравнение регрессии, позволяюшее осуществлять

(C) Siberian Federal University. All rights reserved

This work is licensed under a Creative Commons Attribution-NonCommercial 4.0 International License (CC BY-NC 4.0).

* Corresponding author E-mail address: vnatali59@mail.ru, dagrievna@mail.ru 
выбор условий для протекания с необходимой скоростью химических прочессов, имеющих место в металлургической практике.

Ключевые слова: медь, цинк, латунь, вторичная переработка.

\section{Введение}

Использование благородных металлов в различных областях народного хозяйства с каждым годом возрастает, что требует еще большего их количества. Благородные металлы также до сих пор добывают из рудного сырья, но его запасов становится все меньше и меньше, и с экономической стороны это невыгодно. Поэтому для получения данного вида металлов предлагается использование вторичного сырья. Таким видом вторичного сырья является электронный лом гражданского и военного назначений. В нем содержится гораздо больше благородных металлов, чем в руде, что служит ключевым фактором в развитии производства по переработке вторичного сырья [1].

В настоящее время при вторичной переработке используют многокомпонентный лом, который сложно перерабатывать; например, сухие батареи требуют предварительного отделения марганца и ртути от меди и цинка [2]. Поэтому появляется необходимость разработать новые эффективные технологии, позволяющие не только получать драгоценные металлы, но также извлекать цветные металлы, тем самым повышая рентабельность производства [3].

Основные виды вторичного сырья - лом электронных систем военной техники, печатные платы, смешанный лом электронных приборов, ЭВМ, элементы переключения, транзисторные и стеклянные изоляторы. Переработке подвергается как смешанный лом, так и отдельные его элементы и узлы, в том числе и медный шлак $[4,5]$.

Значительная часть электронного лома военного и гражданского назначения, содержащего драгоценные металлы, в качестве «подложки» содержит латунь. Латунь - это двойной или многокомпонентный сплав на основе меди с добавлением цинка. Иногда в составе латуни находится олово, никель, свинец и другие элементы. По сравнению с чистой медью коррозийная стойкость и прочность у латуни выше. Также латунь можно найти в автомобильных запчастях, системах обогрева и кондиционирования, кабелях и деталях электрооборудования [6].

Таким образом, лом, содержащий латунь, как правило, многокомпонентный, что обуславливает применение самых различных подходов к его переработке.

Существуют разнообразные технологии по переработке лома, содержащего драгоценные металлы, анализ которых показал [7], что пирометаллургические операции не обеспечивают глубокое извлечение благородных металлов. Исходя из этого, на практике применяют гидрометаллургические процессы, которые основаны на вскрытии лома азотной кислотой. Но эти процессы приводят к большим потерям благородных металлов.

Таким образом, разработка новых технологических процессов, способствующих повышению извлечения благородных металлов при переработке электронного лома, остается актуальной и сейчас. Целью настоящей работы явилось исследование условий гидрометаллургического растворения неблагородной металлической основы - медно-цинкового сплава в азотно-сернокислых растворах. Основная задача исследования - при использовании латунных пластин как модели неблагородной основы электронного лома, содержащего благородные металлы, определить скорость перехода меди и цинка в азотно-сернокислые растворы.

$$
-215-
$$




\section{Обоснование плана проведения факторного эксперимента и факторов,}

\section{включаемых в эксперимент}

Взаимодействие металлов с азотной кислотой - сложный процесс, механизм которого включает несколько стадий, в зависимости от кислотности среды конечным продуктом может являться как моно-, так и диоксид азота:

$$
\begin{aligned}
& \mathrm{Me}+4 \mathrm{H}^{+}+2 \mathrm{NO}_{3}^{-}=\mathrm{Me}^{2+}+2 \mathrm{NO}_{2}+2 \mathrm{H}_{2} \mathrm{O}, \\
& 3 \mathrm{Me}+8 \mathrm{H}^{+}+2 \mathrm{NO}_{3}^{-}=3 \mathrm{Me}^{2+}+2 \mathrm{NO}+4 \mathrm{H}_{2} \mathrm{O},
\end{aligned}
$$

где $\mathrm{M}-\mathrm{Cu}, \mathrm{Zn}, \mathrm{Ni}$ и др.

На основании анализа данного уравнения химической реакции были выделены два основных фактора, позволяющих влиять на скорость растворения: кислотность раствора, концентрация нитрат-ионов. Данные факторы контролируемы и управляемы, что позволило использовать их в качестве переменных при составлении плана активного эксперимента. Зависимой переменной выбрана скорость растворения медно-цинкового сплава.

Скорость элементарной химической реакции ( $\omega)$ связана с концентрациями реагентов зависимостью

$$
\omega=\Pi C_{i} b_{i}
$$

где $\mathrm{C}$ - концентрация, моль/дм³ ; $\mathrm{b}$ - порядок реакции по реагенту.

При логарифмировании данного уравнения можно получить линейное уравнение

$$
\log (\omega)=b_{1} \log \left(C_{1}\right)+b_{2} \cdot \log \left(C_{2}\right)+\ldots+b_{k} \cdot \log \left(C_{k}\right),
$$

анализ которого показывает, что при нахождении зависимости скорости растворения от концентрации реагентов целесообразно пользоваться не концентрациями реагентов, а их логарифмами.

Для построения линейной модели достаточно изменять факторы на двух уровнях. Таким образом, при варьировании двух факторов (концентрация нитрат-ионов и кислотности среды) на двух уровнях необходимо поставить четыре основных и несколько дублирующих опытов в центре плана. В табл. 1 приведены принятые нами для проведения эксперимента значения пределов варьирования концентрации $\mathrm{H}^{+}-$и $\mathrm{NO}_{3}{ }^{-}$-ионов, а также значения центра факторного пространства в натуральном и в логарифмическом масштабе. План проведения эксперимента в безразмерном и натуральном масштабах представлен в табл. 2, где четыре основных опыта по-

Таблица 1. Пределы варьирования факторов и центр факторного пространства

Table 1. The limits of variation and the center of the factor space

\begin{tabular}{|l|c|c|c|c|}
\hline $\begin{array}{c}\text { Значение в плане } \\
\text { эксперимента }\end{array}$ & $\begin{array}{c}\mathrm{H}^{+}, \\
\text {моль/дм }\end{array}$ & $\begin{array}{c}\mathrm{NO}_{3}^{-}, \\
\text {моль/дм }\end{array}$ & $\begin{array}{c}\log \left(\mathrm{H}^{+}\right), \\
{[\text {моль/дм }}\end{array}$ & $\begin{array}{c}\log \left(\mathrm{NO}_{3}^{-}\right), \\
{\left[\text {моль/дм }^{3}\right]}\end{array}$ \\
\hline Максимальное значение & 4,0 & 1,0 & 0,60 & 0,00 \\
\hline Минимальное значение & 1,0 & 0,5 & 0,00 & $-0,30$ \\
\hline Центр плана & 2,0 & 0,7 & 0,30 & $-0,15$ \\
\hline
\end{tabular}


Таблица 2. План проведения эксперимента

Table 2. Plan of the experiment

\begin{tabular}{|c|c|c|c|c|}
\hline \multirow{2}{*}{ Номер опыта } & $\mathrm{x}_{1}$ & $\mathrm{x}_{2}$ & $\mathrm{H}^{+}$, моль/дм & $\mathrm{NO}_{3}{ }^{-}$, моль/дм $^{3}$ \\
\cline { 2 - 5 } & \multicolumn{2}{|c|}{ Безразмерный масштаб } & \multicolumn{2}{|c|}{ Натуральный масштаб } \\
\hline 1 & +1 & +1 & 4,0 & 1,5 \\
\hline 2 & +1 & -1 & 4,0 & 0,5 \\
\hline 3 & -1 & +1 & 1,0 & 1,5 \\
\hline 4 & -1 & -1 & 1,0 & 0,5 \\
\hline 5 & 0 & 0 & 2,0 & 0,7 \\
\hline 6 & 0 & 0 & 2,0 & 0,7 \\
\hline
\end{tabular}

зволяют произвести варьирование двух факторов на двух уровнях, два дополнительных опыта необходимы для оценки воспроизводимости результатов и проверки адекватности полученного уравнения регрессии [8].

Данный план позволяет получить взаимосвязь скорости перехода меди и/или цинка в раствор в виде

$$
\log (\omega)=b_{1} \cdot \log \left(\mathrm{H}^{+}\right)+b_{2} \cdot \log \left(\mathrm{NO}_{3}^{-}\right)+b_{12} \cdot \log \left(\mathrm{H}^{+}\right) \cdot \log \left(\mathrm{NO}_{3}{ }^{-}\right)
$$

\section{Методика выполнения эксперимента}

Исходным материалом, моделирующим неблагородную основу электронного лома, содержащего благородные металлы, являлся медно-цинковый сплав, содержащий 60 \% меди и 40 \% цинка. В качестве окислителя были выбраны нитрат-ионы, концентрация которых в соответствии с представленным выше планом эксперимента менялась от 0,5 до 1,0 моль/дм², а за счет присутствия серной кислоты (от 1 до 4 моль/дм³) варьировалась кислотность среды.

Изучение кинетики растворения образцов проводили по следующей методике. В стеклянные колбы заливали $50 \mathrm{~cm}^{3}$ раствора с заданным соотношением $\mathrm{NO}_{3}^{-}-$и $^{+}$-ионов, при этом необходимое соотношение вышеупомянутых ионов подбирали, варьируя соотношение серной кислоты, азотной кислоты и нитрата натрия. Образцы медно-цинкового сплава толщиной 0,05 см и площадью около $10 \mathrm{~cm}^{2}$ помещали в азотно-сернокислые растворы и ставили на встряхиватель. По истечении заданного интервала времени образцы вынимали из раствора, промывали дистиллированной водой, просушивали в сушильном шкафу до постоянной массы, взвешивали с точностью до третьего знака после запятой. В растворах определяли содержание меди и цинка. Далее эту же пластину медно-цинкового сплава помещали в свежую порцию раствора с идентичной концентрацией $\mathrm{NO}_{3}^{-}-$и $\mathrm{H}^{+}$-ионов.

Скорость растворения образцов может быть определена по убыли массы. Однако такой метод слишком груб и не позволяет раздельно определить переход составляющих компонентов сплава в раствор. Для раздельного определения скорости перехода меди и цинка в раствор устанавливали концентрацию меди в растворе методом йодометрического титрования с крахмалом в качестве индикатора [9], а суммарное содержание меди и цинка - методом комплексонометрического титрования комплексоном III с пиридилазонафтолом в качестве индикатора 
[10]. Погрешность отдельного аналитического измерения оценивали, выполняя по два параллельных определения содержания меди и цинка в растворе.

\section{Кинетические кривые перехода меди и цинка в азотно-сернокислые растворы}

Графики изменения концентрации меди в растворе от времени, отражающие результаты расчетов кумулятивного накопления ионов $\mathrm{Cu}^{2+}$ при растворении медно-цинкового сплава в азотно-сернокислых растворах, представлены на рис. $1 a$. Аналогичные данные для кумулятивного накопления ионов $\mathrm{Zn}^{2+}$ приведены на рис. 16 .

Скорость растворения рассчитывали по начальным участкам кинетических кривых как наклон графика в координатах количество перешедшей меди и/или цинка в раствор - время, $\kappa \Gamma / \mathrm{M}^{2} \cdot \mathrm{c}$.

Оценки коэффициентов $b_{i}$ могут быть найдены на основании матричных преобразований, эквивалентных применению метода наименьших квадратов:

$$
\mathrm{B}=\left(\mathrm{X}^{\mathrm{T}} \cdot \mathrm{X}\right)^{-1} \cdot \mathrm{X}^{\mathrm{T}} \cdot \mathrm{Y},
$$

где X - матрица условий эксперимента; Y - матрица результатов опытов; В - матрица неизвестных коэффициентов.

Подстановка в уравнение (6) матрицы условий проведения экспериментов

$$
\mathrm{X}=\left|\begin{array}{llll}
+1 & +1 & +1 & +1 \\
+1 & +1 & -1 & -1 \\
+1 & -1 & +1 & -1 \\
+1 & -1 & -1 & +1
\end{array}\right|
$$

и результатов расчета скорости перехода меди и цинка в раствор в форме $\log (\omega)$, [кг/м $\left.{ }^{2} \mathrm{c}\right]$
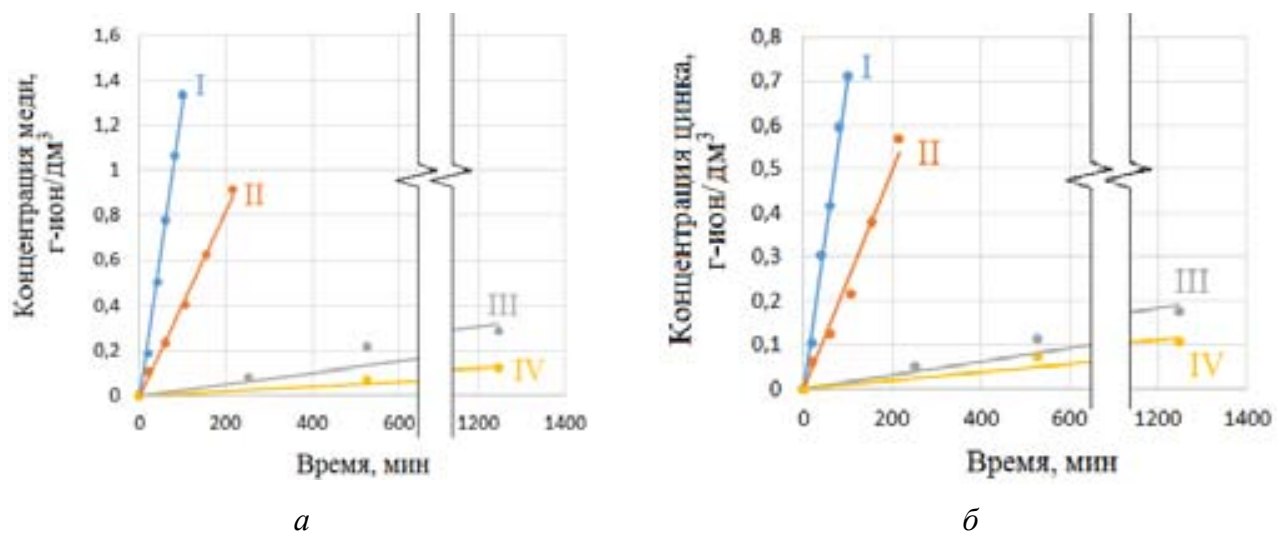

Концентрации реагентов, моль/дм ${ }^{3}: \mathrm{I}_{-} \mathrm{H}^{+}-4,0, \mathrm{NO}_{3}^{-}-1,5 ; \mathrm{II}-\mathrm{H}^{+}-4,0, \mathrm{NO}_{3}^{-}-0,5$;

$$
\text { III }-\mathrm{H}^{+}-1,0, \mathrm{NO}_{3}^{-}-1,5 ; \mathrm{IV}-\mathrm{H}^{+}-1,0, \mathrm{NO}_{3}^{-}-0,5
$$

Рис. 1. Кинетические кривые перехода меди (а) и цинка (б) в раствор при окислении медно-цинкового сплава в азотно-сернокислых растворах

Fig. 1. Kinetic curves of transition of copper (a) and zinc (б) into solution during oxidation of copper-zinc alloy in nitrogen-sulfuric acid solutions 


$$
\mathrm{Y}_{\mathrm{Cu}}=\left|\begin{array}{c}
-4,18 \\
-4,79 \\
-5,42 \\
-5,91
\end{array}\right|, \quad \mathrm{Y}_{\mathrm{Zn}}=\left|\begin{array}{c}
-4,30 \\
-5,09 \\
-5,76 \\
-6,00
\end{array}\right|
$$

позволяет получить соответствующие коэффициенты уравнения регрессии.

$$
\mathrm{B}=\left|\begin{array}{l}
b_{0} \\
b_{1} \\
b_{2} \\
b_{12}
\end{array}\right| .
$$

Для скорости перехода меди и цинка в раствор имеем следующие коэффициенты:

$$
\mathrm{B}_{\mathrm{Cu}}=\left|\begin{array}{c}
-5,08 \\
0,59 \\
0,27 \\
0,03
\end{array}\right|, \quad \mathrm{B}_{\mathrm{Zn}}=\left|\begin{array}{c}
-5,28 \\
0,60 \\
0,26 \\
0,07
\end{array}\right| .
$$

Анализ полученных коэффициентов позволяет констатировать, что переход меди и цинка в раствор происходит синхронно. Наибольшее влияние на скорость перехода меди в раствор оказывает не концентрация окислителя ( $\mathrm{NO}_{3}^{-}$-ионов), а кислотность (концентрация $\mathrm{H}^{+}$-ионов) среды. Фактор совместного влияния концентрации окислителя и $\mathrm{H}^{+}$-ионов практического значения не имеет, что подтверждается меньшим значением коэффициента двойного взаимодействия $\mathrm{b}_{12}$ по сравнению с коэффициентами $\mathrm{b}_{1}$ и $\mathrm{b}_{2}$.

Уравнения, связывающие скорость перехода меди и/или цинка в азотно-сернокислые растворы с выбранными факторами, можно представить в виде, удобном для расчета скорости растворения медно-цинкового сплава, содержащего 60 \% меди и 40 \% цинка:

$$
\begin{aligned}
& \log \left(\omega_{\mathrm{Cu}}\right), \frac{\mathrm{K} \Gamma}{\mathrm{M} \cdot \mathrm{c}}=-5,08+0,59 \cdot \frac{\log \left(\mathrm{H}^{+}\right)-0,3}{0,3} \\
& +0,27 \cdot \frac{\log \left(\mathrm{NO}_{3}^{-}\right)+0,15}{0,15}+0,03 \cdot \frac{\log \left(\mathrm{H}^{+}\right)-0,3}{0,3} \cdot \frac{\log \left(\mathrm{NO}_{3}^{-}\right)+0,15}{0,15}, \\
& \log \left(\omega_{\mathrm{Zn}}\right), \frac{\mathrm{K} \Gamma}{\mathrm{M} \cdot \mathrm{c}}=-5,28+0,60 \cdot \frac{\log \left(\mathrm{H}^{+}\right)-0,3}{0,3} \\
& +0,26 \cdot \frac{\log \left(\mathrm{NO}_{3}^{-}\right)+0,15}{0,15}+0,07 \cdot \frac{\log \left(\mathrm{H}^{+}\right)-0,3}{0,3} \cdot \frac{\log \left(\mathrm{NO}_{3}^{-}\right)+0,15}{0,15} .
\end{aligned}
$$

Анализ данных коэффициентов показывает, что с увеличением как кислотности, так и концентрации нитрат-ионов в растворе скорость растворения металлов увеличивается.

Данный вывод удобно продемонстрировать, представив полиномиальную зависимость в виде объемной диаграммы (рис. 2).

\section{Выводы}

Исследована скорость перехода меди и цинка из медно-цинковой пластины, моделирующей неблагородную основу электронного лома, содержащего благородные металлы, в азотносернокислых растворах. Эксперименты проведены на основании выбранного полного факторного плана для двух факторов на двух уровнях с двумя параллельными опытами в центре плана.

$$
-219-
$$




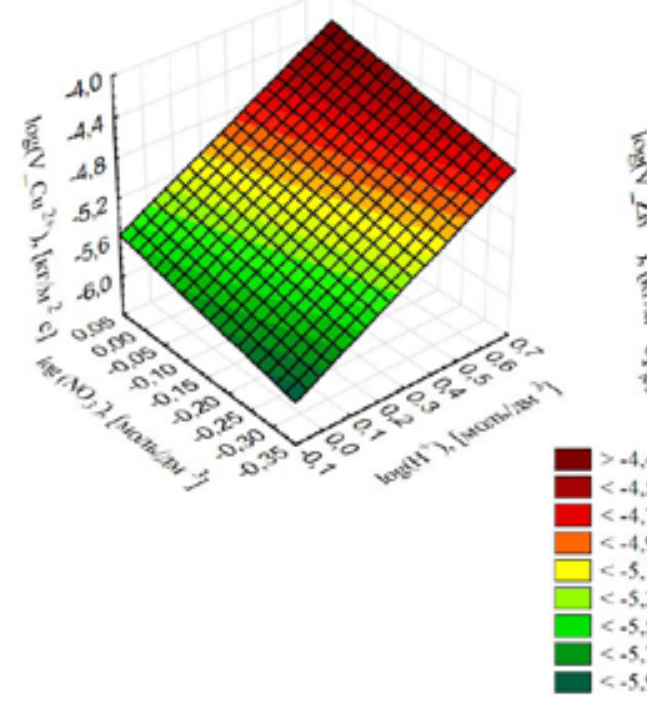

a

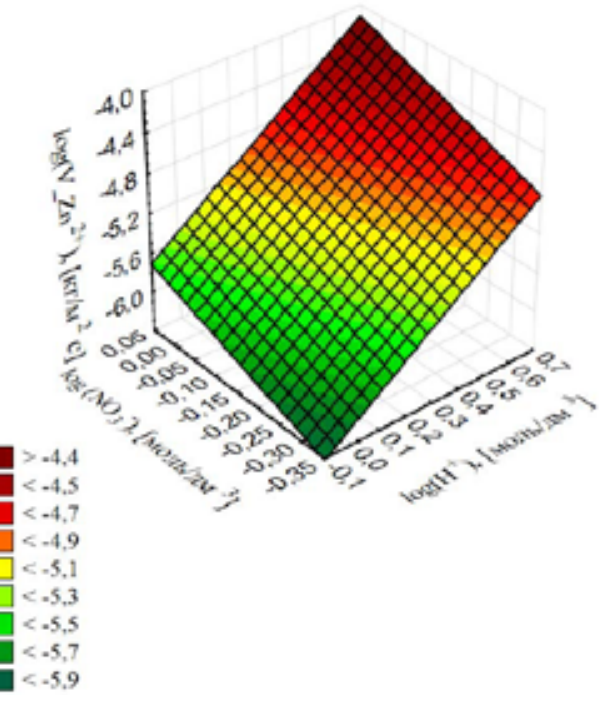

6

Рис. 2. Скорость перехода меди (а) и цинка (б) в раствор при окислении медно-цинковой пластины в азотно-сернокислых средах в зависимости от концентрации $\mathrm{NO}_{3}^{-}-$и $\mathrm{H}^{+}$-ионов

Fig. 2. The rate of transition of copper (a) and zinc (б) into solution during oxidation of copper-zinc plate in nitrogen-sulfuric acid media depending on the concentration of $\mathrm{NO}_{3}{ }^{-}$and $\mathrm{H}^{+}$ions

Получена математическая модель, позволяющая рассчитать скорость перехода меди и цинка в азотно-сернокислые растворы при варьировании концентрации $\mathrm{H}^{+}$-ионов от 1 до 4 моль/дм³ и $\mathrm{NO}_{3}{ }^{-}$-ионов от 0,5 до 1,0 моль/дм³ .

Выявлено, что при совместном варьировании концентрации $\mathrm{H}^{+}$-ионов от 1 до 4 моль/дм ${ }^{3}$ и $\mathrm{NO}_{3}{ }^{-}$-ионов от 0,5 до 1,0 моль/дм ${ }^{3}$ скорость перехода меди в раствор составляет $(1 \div 65) \cdot 10^{-6}$, а цинка $-(0,8 \div 42) \cdot 10^{-6} \kappa \Gamma / \mathrm{M}^{2} \mathrm{c}$.

Показано, что математические модели позволяют правильно подобрать оборудование и осуществить выбор условий для протекания с необходимой скоростью химических процессов, имеющих место в металлургической практике.

\section{Список литературы}

[1] Колмакова А.А. Физико-химические закономерности прочессов вскрытия электронного лома, содержащего благородные металлы, смесью серной и азотной кислот : автореф. дис. ... канд. техн. наук. Красноярск, 2004, 20 с. [Kolmakova A.A. Physico-chemical patterns of the opening of electronic scrap containing precious metals with a mixture of sulfuric and nitric acids, Thesis dis ... cand. of tech. Sci. Krasnoyarsk, 2008, 20 p. (In Russian)].

[2] Masakatsu Hasegawa Ryo Ueyama Yoshiaki Kashiwaya Tetsuji Hirato Recovery of Zinc from Used Alkali-Manganese Dry Cells, Journal of Sustainable Metallurgy June 2015, 1(2), $144-150$.

[3] Лолейт С.И. Разработка экологически чистых технологий комплексного извлечения благородных и иветных металлов из электронного лома : Дис. ...Д-ра техн. наук. Москва, 2009, 234 c. [Lolite S.I. The development of environmentally friendly technologies for the complex 
extraction of precious and non-ferrous metals from electronic scrap, Dis. ... doc. of tech. Sci. Moscow, 2009, 234 p. (In Russian)]

[4] Pincha Torkittikul, Thanongsak Nochaiya, Watcharapong Wongkeo, Arnon Chaipanich Utilization of coal bottom ash to improve thermal insulation of construction material, Journal of material cycles and waste management, 2017, 19(1), 305-317.

[5] Krishna Murari, Rafat Siddique, K.K. Jain Use of waste copper slag, a sustainable material, Journal of Material Cycles and Waste Management, 2015, 17(1), 13-26.

[6] Christoph Nobel, Uwe Hofmann, Fritz Klocke, Drazen Veselovac Experimental investigation of chip formation, flow, and breakage in free orthogonal cutting of copper-zinc alloys, The International Journal of Advanced Manufacturing Technology, 2016, 84(5), 1127-1140.

[7] Электротехника: необходимость переработки электронного лома [Электронный ресурс]. - Режим доступа: http://vtorothodi.ru/pererabotka/pererabotka-elektronnogo-loma [Electrical engineering: the need to process electronic scrap [Electronic resource]. Access: -http://vtorothodi.ru/ pererabotka/pererabotka-elektronnogo-loma ]

[8] Ходасевич Г.Б. Планирование эксперимента [Электронный ресурс]: Режим доступа: http://pds.sut.ru/electronic_manuals/pe [Khodasevich G.B. Experiment Planning [Electronic resource]: Access: http://pds.sut.ru/electronic_manuals/pe ]

[9] Подчайнова В.Н., Симонова Л.Н. Медь. М.: Наука, 1990. 279 с. [Podchaynova V.N., Simonova L.N. Copper. M.: Science, 1990. 279 p. (in Russian)]

[10] Живописцев В.П., Селезнева Е.А. Аналитическая химия иинка. М.: Наука, 2007. 305 с. [Zhivopiscev V.P., Selezneva E.A. Analytical chemistry of zinc. M.: Science, 2007. 305 p.] 